
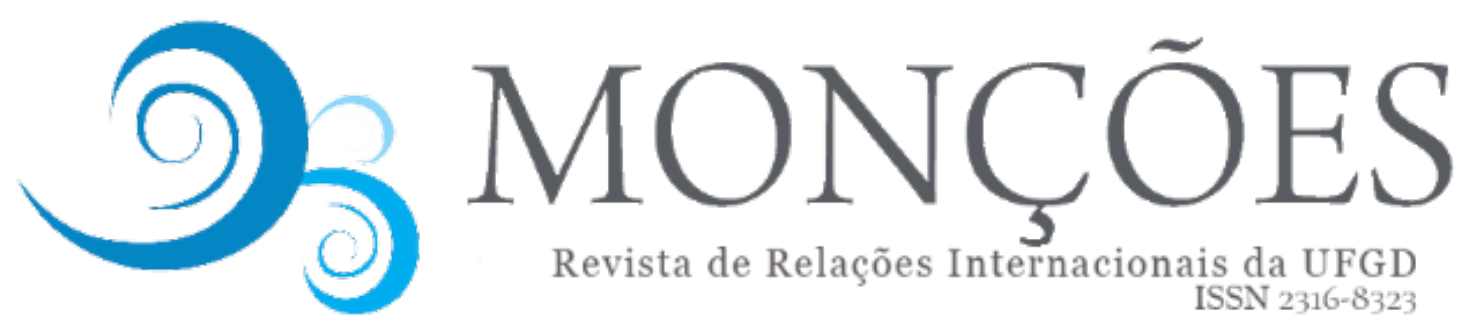

Revista de Relações Internacionais da UFGD

ISSN 2316-8323

\title{
OS LIMITES DA GOVERNANÇA GLOBAL: A GOVERNAMENTALIDADE COMO ALTERNATIVA ANALÍTICA
}

\author{
VITOR FURTADO JERÔNIMO VELOSO \\ Doutorando em Relações Internacionais pelo Programa de Pós-Graduação em Relações \\ Internacionais San Tiago Dantas (Unesp, Unicamp, Puc-SP).
}

\begin{abstract}
RESUMO: No presente artigo, busco demonstrar as possíveis contribuições que o conceito de "governamentalidade" pode trazer para a área de Relações Internacionais, especificamente, na discussão sobre governança. Para tanto, faço um mapeamento da utilização do conceito de governança global na área, suas diferentes utilizações, e como ele se insere na literatura. Posteriormente, traço algumas críticas ao termo, seja por sua amplitude conceitual, que supostamente causou seu "esvaziamento", ou por sua capacidade de explicar as mudanças ocorridas na política internacional em diferentes momentos históricos. Sendo assim, apesar de sua importante contribuição conceitual e como agenda de pesquisa, a governança global encontrou certos limites em explicar as diferentes interações entre os atores públicos e privados. Pautado nisso, trago algumas contribuições dos estudos da governamentalidade para as Relações Internacionais, e sobre as possibilidades de pesquisa e questionamento que eles podem trazer. Sendo assim, o objetivo do presente artigo é trazer um pouco mais do debate "governança versus governamentalidade" tão pouco abordado e discutido no Brasil. Portanto, viso fomentar o interesse por pesquisas utilizando tal referencial teórico pensando a "governamentalidade" não como uma forma de "superar" a governança, mas como uma lente analítica alternativa para a esfera internacional.
\end{abstract}

PALAVRAS-CHAVE: governança global; governamentalidade; debate.

\section{THE LIMITS OF GLOBAL GOVERNANCE: GOVERNMENTALITY AS AN ANALYTICAL ALTERNATIVE}

ABSTRACT: In this present article, I seek to demonstrate the possible contributions that the concept of "governmentality" can bring to the International Relations area, specifically, in the discussion about governance. To this end, I map the use of the concept of global governance in the area, its different uses and how it fits in the literature. Subsequently, I draw some criticism of the term, either because of its conceptual breadth, which supposedly caused its "emptying", or for its ability to explain the changes in international politics at different historical times. Thus, despite its important conceptual contribution and research agenda, global governance has found certain limits in explaining the different interactions between public and private actors. Based on this, I bring some important contributions of governmentality studies to International Relations, and about the possibilities of research and questioning that they can bring. The aim of this article is to bring a little more of the debate "governance versus governmentality" so little approached and discussed in Brazil. Therefore, I aim to foster interest in research using such a theoretical framework, thinking of "governmentality" not as a way of "overcoming" governance, but as an alternative analytical lens for the international sphere.

KEYWORDS: global governance; governmentality; debate. 


\section{Introdução}

Na literatura de Relações Internacionais (RI), a governança passou a ser um termo central na tentativa de explicar a organização da política mundial e, principalmente, as mudanças na relação entre atores públicos e privados. Associado ao contexto de fim da Guerra Fria e, consequentemente, atrelado ao conceito de globalização, o termo "governança" ganhou notoriedade nos anos 90. As contribuições de Rosenau e Czempiel (1992), assim como a criação do periódico Global Governance, em 1995, foram essenciais para dar início ao que se tornaria uma verdadeira agenda de pesquisa nas análises de política internacional. Embora tal agenda tenha se expandido durante esse período, as preocupações com a questão da governança e globalização tem raízes ainda mais profundas.

Como é comum no surgimento de novos termos que adquirem popularidade em diferentes áreas, não existe uma definição clara e concisa sobre o que é a governança (BIERMANN; SIEBENHÜNER; SCHREYÖGG, 2009). O termo adquiriu diferentes significados e interpretações dependendo da maneira como é utilizado (BÖRZEL; RISSE, 2005; DINGWERTH; PATTBERG, 2006). As "governanças", como colocou Eagleton-Pierce (2014), se multiplicaram e podem ser encontradas em todos os tipos de configurações e fóruns institucionais, permeando comunidades políticas e agendas de pesquisa acadêmica. Ainda segundo ele, as principais derivações do conceito são a "governança global" e a "good governance".

A polissemia do conceito, somado a seu uso indiscriminado e pouco definido, possibilitou o surgimento de críticas acerca de um "esvaziamento" da governança (DINGWERTH; PATTBERG, 2006). Talvez, a principal delas foi a crítica feita por Larry Finkelstein (1995). Focando sua crítica na "governança global", o autor afirmou que o termo foi aplicado a uma variedade de questões internacionais e de forma, no mínimo, desordenada e confusa. Neste sentido, foi tão incisivo que ao afirmar que o conceito foi aplicado a quase todas as questões internacionais, ele "pareceria ser praticamente qualquer coisa" (FINKELSTEIN, 1995, p. 368, trad. Nossa). Apesar de concordarem com o "esvaziamento" do termo, Dingwerth e Pattberg (2006) sustentam sua utilidade para identificar e descrever as mudanças na política mundial evidenciando novas ferramentas para compreender as transformações a nível transnacional, diferenciando-se das abordagens mais tradicionais. Portanto, para 
desenvolver teorias mais coerentes da governança global, seria necessário um esclarecimento conceitual por parte dos autores que a utilizam.

Diferente das críticas que sustentam a necessidade de um maior rigor na definição do termo governança e, mais especificamente, da governança global, diferentes autores se preocuparam em questionar sua capacidade explicativa. Alguns deles, de inspiração foucaultiana, advogaram em favor da utilização do conceito de "governamentalidade" cunhado pelo filósofo francês. É nesse ponto que o artigo se insere. Em consonância com as críticas feitas por tais autores, o presente trabalho tem como intuito apresentar a contribuição da ótica da governamentalidade para a análise da política internacional. Compreendendo que o conceito de governança global não somente possui uma "promiscuidade" conceitual, como também, não consegue captar as diferentes formas com que a sociedade civil passou a atuar na esfera internacional, faço um mapeamento das análises feitas através da ótica da governamentalidade. Por fim, aponto como tal interpretação pode ser uma alternativa diferente e produtiva para se analisar as mudanças na atuação da sociedade civil na política internacional.

Posto isso, o presente artigo contribui com tal literatura ao apontar como a ótica da governamentalidade vem contribuindo, e pode contribuir ainda mais, para analisar as transformações na política internacional. Para tanto, o trabalho é divido em três seções. Na primeira, reviso os conceitos de governança global e suas utilizações nas diferentes áreas dentro das Relações Internacionais. Já na segunda seção, trato das críticas feitas ao termo e suas limitações. De outro modo, trato da inserção da ótica da governamentalidade como alternativa ao conceito de governança nas Relações Internacionais, quais suas contribuições para o campo de estudo, e que tipo de abordagens foram feitas até o momento. Por fim, na última seção concluo comentando como os estudos sobre a governamentalidade podem ser importantes para ampliar as fronteiras de análise dentro da disciplina de Relações Internacionais.

\section{As “Governanças”: definindo a governança global}


A multiplicidade de interpretações que o termo 'governança' adquiriu nas diferentes áreas do conhecimento, dentre elas, a de Relações Internacionais, é suscintamente traduzida pelo que Eagleton-Pierce (2014) chamou de 'governanças". Segundo o autor, nas últimas décadas o conceito foi repensado e implantado em diversas áreas e instituições e, por vezes, utilizado por atores que possuem fins diferentes e contraditórios. Assim, a expressão ganhou o status de referência para explicar as mudanças no contexto internacional. Dito isso, nesta seção farei uma revisão das diversas conceituações que o termo 'governança global' adquiriu nas últimas décadas. Portanto, o objetivo é apresentar as diferentes formas e interpretações que o conceito assume, qual objeto tenta analisar, e em qual linha de pesquisa está inserido.

Desde os anos 90, a preocupação com as mudanças globais é uma das principais características do campo das Relações Internacionais (HEWSON; SINCLAIR, 1999). O fim da Guerra Fria e os questionamentos sobre a natureza e as implicações da globalização impulsionaram a formação e o crescimento de uma verdadeira agenda de pesquisa da governança global. Para Finkelstein (1995), o conceito era demasiado amplo e complexo, sendo difícil utilizá-lo como ferramenta analítica. Seria necessário determinar um significado mais preciso do termo. Oposto a tal interpretação, Hewson e Sinclair (1999) defenderam que uma noção mais abrangente sobre a mudança global seria essencial. Sendo assim, os diferentes usos do conceito de governança global teriam o potencial de iluminar um aspecto da mudança que continua ocorrendo na política mundial.

Compreendendo que a governança global não foi um fenômeno novo da década de 1990, mas uma realidade histórica, Weiss e Wilkinson (2014) afirmam que para entendermos como o poder e autoridade são exercidos pelos atores através de diferentes mecanismos, precisamos analisar as mudanças ocorridas nas formas de governança nos diferentes contextos históricos. Sendo assim, para ser uma ferramenta analítica legítima, ela precisaria explicar a mudança não apenas no pós-Guerra Fria, mas em outros momentos e circunstâncias históricas.

No entanto, é preciso reconhecer que, de modos distintos, diversos autores tentaram compreender as formas de organização dos atores públicos e privados dentro do cenário internacional (HEWSON; SINCLAIR, 1999; LAKE, 1999). Uma primeira tentativa de monitorar tais mudanças podem ser notada nas abordagens 
sobre a globalização econômica que se concentram em analisar uma inclinação dos Estados para o mercado (THOMPSON; HIRST, 1996; KAHLER, 2013; OHMAE, 1990; ROSENAU, 1995b). Uma segunda manifestação que objetiva compreender as mudanças no cenário internacional pode ser encontrada na literatura sobre regimes internacionais (KEOHANE 1984; KRASNER, 1983; RUGGIE,1982). Já a terceira vertente da literatura foca nas consequências das mudanças contemporâneas nas capacidades das organizações internacionais para enfrentar os problemas mundiais (BUCHANAN; KEOHANE, 2006; KEOHANE, 1988; WEISS, 2000).

Focados em compreender a ascensão de forças políticas que moldam a forma da governança global, alguns autores se empenharam em analisar o crescimento da participação e autoridade dos atores privados no cenário global (CUTLER; HAUFLER; PORTER, 1999; HALL; BIERSTEKER, 2002; KECK; SIKKINK 1998; LEVY; PRAKASH, 2003; HELD; MCGREW, 2002). Outros focaram no poder crescente das elites transnacionais na economia política global e na hegemonia (COX, 1987; GILL, 1994; GRAZ, 2003; OVERBEEK, 2005; VAN DER PIJL, 1998). Por outro lado, algumas abordagens também analisaram o crescimento da participação civil na política internacional através da emergência da 'sociedade civil global' (GORDENKER; 1995; LIPSCHUTZ, 1992; LIPSCHUTZ; MAYER, 1996; SCHOLTE, 2002).

Além dessas, existem ainda diferentes abordagens em relação à governança global, entre elas: abordagens sobre comunidades epistêmicas (HAAS, 1992); interdependência e transnacionalismo (KEOHANE; NYE, 1972; 1977); direito internacional (ABBOTT; SNIDAL, 2000); redes de políticas públicas (REINICKE; DENG, 2000); governança ambiental (BIERMANN; PATTBERG, 2012; YOUNG, 1994); padrões e normas internacionais (FINNEMORE; SIKKINK, 1998; MURPHY; YATES, 2009); migrações (BETTS, 2011); agricultura e alimentação (CLAPP; FUCHS, 2009); segurança (DUFFIELD, 2014); questões humanitárias (BENEDETTI; WASHBURN, 1999); regionalismo (TELÒ, 2013; THAKUR; WEISS; WILKINSON, 2014); feminismo e gênero (HAFNER-BURTON; POLLACK, 2002); internet (DREZNER, 2004); direitos humanos (MERRY; CONLEY, 2011); entre outros. Ademais, para além das $\mathrm{RI}$, podemos encontrar as raízes teóricas do conceito de governança em diversas outras áreas, como economia, estudos organizacionais, estudos de desenvolvimento, ciência política, administração pública e teóricos da 
inspiração foucaultiana (STOKER, 1998). Sendo assim, a literatura sobre governança é um tanto quanto eclética e relativamente desconexa (JESSOP, 1995).

A Commission on Global Governance (1995, p.1, trad. Nossa) definiu governança global como "a soma das muitas formas pelas quais indivíduos e instituições, públicos e privados, gerenciam seus assuntos comuns". Analisando o modo como as organizações não governamentais influenciam ou redefinem a governança global, Weiss e Gordenker (1996) a definem como um conjunto de esforços para responder às questões políticas que vão além das capacidades dos estados de abordar individualmente. Já Young (1994) define governança como "estabelecimento e funcionamento de instituições sociais capazes de resolver conflitos, facilitando a cooperação ou, mais genericamente, atenuando a ação coletiva e problemas em um mundo de atores interdependentes" (YOUNG, 1994, p.15, trad. Nossa).

Bastante consolidada na literatura a respeito da área é a contribuição de James Rosenau (1992), em trazer à tona o tema da governança global para o debate na Relações Internacionais. De partida, o autor diferencia 'governança' de 'governo' argumentando que não são sinônimos como outros autores tratam. Segundo ele, ambos se referem a um comportamento orientado por objetivos, intencional. $\mathrm{O}$ que os diferencia é que o governo é apoiado por uma autoridade formal que assegura a implementação de políticas devidamente constituídas. Já a governança, apoia-se em objetivos compartilhados que podem (ou não) advir de autoridade formal (ROSENAU, 1992). Portanto, ela se manifesta como algo mais abrangente englobando instituições governamentais, mecanismos informais e não governamentais. Logo, é possível falar do que Rosenau chamou "governança sem governo" - mecanismos reguladores em um dado setor que funciona efetivamente, mesmo não sendo dotados de autoridade formal.

Nesse sentido, sugerindo que a governança é eficaz por não se basear em uma aceitação majoritária, Rosenau atrela a noção de governança à de ordem. Portanto, o conceito de 'governança sem governo' seria frutífero para o estudo da política mundial, na medida em que a autoridade centralizada está ausente, e exista um mínimo de ordem na política mundial. Dada uma ordem que carece de uma autoridade centralizada com a capacidade de impor decisões em escala global, conclui-se que uma tarefa primordial de investigação é a de examinar até que ponto 
as funções normalmente associadas à governança são executadas na política mundial sem as instituições de governo. Assim, governança e ordem seria duas faces da mesma moeda, não podendo haver governança sem ordem, nem ordem sem governança (ROSENAU, 1992).

Em seu texto, Rosenau não utiliza precisamente a expressão "governança global", porém, quando menciona uma certa 'ordem que carece de uma autoridade centralizada com capacidade de impor decisões em escala global' (ROSENAU, 1992, p.7, trad. Nossa), seria, em termos gerais, o conceito de governança global (BIERSTEKER, 2010). Por fim, ele tratou de diferenciar a governança e o conceito de regimes internacionais, bastante influente no início dos anos 90 . O autor reconheceu que assim como a governança, os regimes são concebidos como arranjos que sustentam e regulam as atividades a nível internacional. Do mesmo modo, eles também partem do pressuposto que atores governamentais e nãogovernamentais concordam que a cooperação em busca de objetivos compartilhados justifica a aceitação dos princípios, normas, regras e procedimentos que diferenciam e dão coerência a seus regimes.

Criticando a definição proposta por Rosenau, Biersteker (2010) argumentou que ela seria demasiado ampla e teria relativamente pouco a dizer sobre quem ou o que toma as decisões, ou precisamente como o enforcement ocorre. Com o intuito de estreitar o conceito, Dingwerth e Pattberg (2006) distinguiram dois usos gerais para ele: como um conjunto de fenômenos observáveis; e como um programa político. O primeiro, chamado por eles de "uso analítico", tenta captar a realidade atual (percebida e/ou construída) da política mundial - ex. Rosenau (1992). O uso desse novo termo pode ser entendido como uma resposta às falhas das teorias existentes nas relações internacionais para dar conta das transformações empíricas. Assim, a governança global é compreendida como "um dispositivo heurístico para capturar e descrever a transformação confusa e aparentemente sempre acelerada do sistema internacional", afastando-se das abordagens mais tradições de RI (DINGWERTH; PATTBERG, 2006).

Já o segundo, o "uso normativo", é frequentemente usado para denotar um programa político específico. Assim, o termo expressa uma perspectiva normativa sobre como instituições políticas devem reagir à reduzida capacidade de direção dos sistemas políticos nacionais ou a uma perspectiva crítica que se refere à governança 
global como um discurso - ex. o conceito de governança global cunhado pela Commission on Global Governance (1995). No que se refere à versão mais crítica, aponta-se que a governança global não é um termo livre de valores, mas sim, um conceito altamente politizado no meio de um embate discursivo sobre 'quem decide o que para quem'. Portanto, é um termo que não é uma resposta às falhas do Estado no processo de globalização, e sim, um discurso hegemônico para disfarçar os efeitos negativos do desenvolvimento econômico neoliberal em escala global (DINGWERTH; PATTBERG, 2006).

Analisando a ascensão dos atores privados na governança global, Falkner (2003) afirmou que a governança emergiu de um contexto de interação institucionalizada e de natureza mais permanente. Os atores não somente se baseiam em um comprometimento com as normas estabelecidas pautadas em seus interesses, mas, também, ajustam seu comportamento a partir do reconhecimento da legitimidade do sistema de governança (FALKNER, 2003). O autor apontou que a noção convencional de governança ainda permanece centrada no Estado. Apesar de reconhecer o aumento da participação dos atores privados na governança global, efetivamente, ela ainda depende da autoridade do Estado no estabelecimento e implementação de regimes internacionais.

Portanto, o surgimento da governança privada representa um desafio para os entendimentos estabelecidos da relação entre Estados e atores privados. Isso vai ao encontro da interpretação de Rosenau (1992) de que a política internacional agora é caracterizada como multicêntrica, não mais centrada no Estado. Apesar disso, os Estados são importantes para a sustentação dos sistemas de governança através do reconhecimento. Ou seja, seria equivocado falar em "declínio do Estado" como algumas interpretações sugerem. O que ocorre são diferentes formas de interação entre os diferentes Estados e a governança do setor privado. Portanto, a nova agenda da governança global seria definida por um intrincado elo público-privado em que autoridades públicas e privadas trabalham em conjunto para redefinir os parâmetros da formulação de políticas globais.

Por fim, Biermann, Siebenhüner e Schreyögg (2009) definem o termo governança global como políticas mundiais não mais confinadas aos Estados, mas caracterizadas por uma participação maior de atores que não-estatais, como redes de especialistas, corporações multinacionais, organizações intergovernamentais, 
etc. Por outro lado, ela também é caracterizada pelo surgimento de novas formas de instituições, sendo a política frequentemente organizada em redes e em novas formas de cooperação público-privada negociadas entre estados e entidades nãoestatais. Sendo assim, a governança global é marcada por uma crescente segmentação de diferentes camadas e grupos de implementação de regras, fragmentada verticalmente entre camadas de autoridade supranacionais, internacionais, nacionais e subnacionais e horizontalmente entre diferentes sistemas paralelos de criação de regras mantidos por diferentes grupos de atores. Ou seja, emerge uma governança global "multi-ator" e fragmentada em "multicamadas" com autoridade difusa. As linhas de autoridade se confundem, os níveis de governança mudam e se multiplicam, e diferentes atores se interagem por poder e influência.

Portanto, após essa sintética exposição sobre algumas interpretações do conceito de governança global, podemos notar que um conceito geral e definitivo está longe de ser sedimentado. O que parece ser consenso, tanto para os acadêmicos de Relações Internacionais, quanto das diversas áreas correlatas pelas quais o termo é utilizado, é que governança difere de governo. Em segundo lugar, parece haver certo consenso de que a governança global trouxe à tona a crescente participação de atores não estatais na esfera política internacional. De outro modo, a questão da autoridade a nível transnacional parece estar cada vez mais difusa, e a influência de diferentes atores públicos e/ou privados, sendo um dos fatores causais mais importantes nesse sentido.

Por fim, minha intenção foi expor um pouco da heterogeneidade dos sentidos dados ao termo governança global nas diferentes linhas de pesquisa e áreas às quais ele é aplicado. De outro modo, tentei demonstrar que existem autores que veem essa volatilidade do conceito algo positivo e produtivo, como necessário para se explicar as mudanças ocorridas nas relações internacionais contemporâneas. No entanto, existem aqueles que apontam para a necessidade de se definir o termo de forma mais parcimoniosa e precisa, adequado ao tipo de análise que será feita. Já uma "terceira" linha de autores criticam a eficácia da governança global em explicar os fenômenos mais diversos aos quais o termo se propõe a explicar. Alguns teóricos de inspiração foucaultiana fazem parte desta crítica, apontando a necessidade de um termo que consiga absorver a questão do poder, que segundo eles, falta nas análises da governança global. Será a partir desta última vertente, mais 
especificamente, de autores que utilizam o arcabouço analítico foucaultiano, que seguirei na próxima seção.

\section{As limitações da Governança Global: o debate sobre governamentalidade}

Paralelamente à discussão sobre governança, estudos da governamentalidade já vinham aumentando em outras áreas das ciências sociais, como a sociologia e educação, desde os anos 90. Posteriormente, tal perspectiva, agora como plano de ação o "internacional/global", expandiu para a área de Relações Internacionais (DE LARRINAGA; DOUCET, 2010; METHMANN, 2011). Assim, os teóricos das RI têm descoberto a importância da governamentalidade (PROZOROV, 2004). Para o campo, isso significa um foco nas diferentes instituições, procedimentos, análises e reflexões que visam a população tentando moldar a conduta das pessoas. Assim, diversos estudiosos procuraram compreender a política mundial a partir de tal perspectiva (DEATH, 2013; LIPSCHUTZ, 2005; LIPSCHUTZ; ROWE, 2005; MERLINGEN, 2006; NEUMANN; SENDING, 2010; ROSENOW, 2009; SENDING; NEUMANN, 2006; WALTERS; HAAHR, 2005). A governamentalidade tornou-se então um conceito central dentro de vasta gama de estudos sobre poder, ordem, subjetividade e resistência (LARNER; WALTERS, 2004).

Latham (1999) apontou que até então, diferentemente do poder, a governança não havia sido um termo central de contestação nas ciências sociais e nem na ciência política. O termo possuía um significado que, segundo o autor, era basicamente dado. Para ele, os estudos de Michel Foucault sobre a governamentalidade foram importantes para despertar as críticas ao conceito. Portanto, nesta seção tentarei sistematizar as contribuições feitas pelos estudos da governamentalidade para o debate da governança global dentro das Relações Internacionais, apontando possíveis pontos de diálogo, dissenso, e algumas aplicações de tal lente analítica na área. Para tanto, limito a exposição a áreas temáticas em que os estudos de governamentalidade têm um significado particular para os estudos de política internacional. 


\section{1. $O$ que é governamentalidade}

Demonstrando estranheza que diversos estudos políticos tenham negligenciado a governamentalidade em suas investigações, Walters e Haahr (2005) apontam que tais estudos conectam as teorias de poder e subjetividade de Foucault mais diretamente às questões do Estado e da política do que qualquer uma de suas outras investigações. Portanto, seria importante investigar quais insights e instrumental analítico a governamentalidade poderia oferecer aos estudos da política e das Relações internacionais (SENDING; NEUMANN, 2010). No entanto, uma pergunta importante surge: o que é a governamentalidade ${ }^{1}$ ?

O conceito de governamentalidade foi elaborado por Michel Foucault em um curso ministrado nos anos 1978-79 no Collège de France (publicadas postumamente). Ele representa uma abordagem não convencional aos problemas de governar. Para o filósofo francês, governar não se restringe ao governo político do estado. Governar requer considerar uma totalidade de instituições e práticas pelas quais as pessoas são governadas, da administração à educação (FOUCAULT, 1997, p. 118). Durante suas reflexões houveram mudanças em seus interesses e focos de pesquisa, principalmente, em relação à questão do poder. Logo, sua concepção de governamentalidade surge como uma resposta às mudanças em sua analítica do poder. Foucault passou a questionar as abordagens tradicionais sobre $o$ poder que o tratam como um tipo de direito, posse, ou capacidade de influenciar os indivíduos. Além disso, entende-se que o poder emana de um centro - ex. Estado e sua análise se pauta em entender e explicar como ele se estende verticalmente a outros segmentos sociais (PEREIRA; RAMOS; SANTOS FILHO, 2011). Como aponta Foucault, "o poder não se dá, não se troca nem se retoma, mas se exerce, só existe em ação (...)" (FOUCAULT, 1986, p. 175).

Portanto, se o poder só pode existir em exercício, não faz sentido ele advir de uma instituição, ou indivíduo (ex. governo e Estado). Nesse sentido, o poder é sempre relacional, estendendo-se através das relações sociais pelas diferentes formações discursivas produzindo conhecimento e verdades, e a partir destas,

\footnotetext{
${ }^{1}$ Não é meu objetivo aqui trazer toda a trajetória de Foucault até a cunhagem do termo. Muito menos pretendo fazer uma análise pormenorizada sobre as especificidades do conceito. Para tanto, já existe uma vasta literatura de intérpretes que abordam meticulosamente sobre o assunto (DEAN, 1999; MILLER; ROSE, 2008; LEMKE, 2015).
} 
continuando sua disseminação. De forma clara, Pereira, Ramos e Santos Filho (2011) resumem a relação entre a poder e governamentalidade:

"A analítica do poder em Foucault é um esforço para capturar o poder em exercício e em sua capilaridade social, nas diferentes técnicas, estratégias, táticas e tecnologias de sua manifestação, sempre evitando reduzi-lo à repressão, à violência, a supressão de algo na forma de sanções ou coerção. Assim, ao voltar-se com a ideia de governamentalidade para o Estado, ele o faz não por percebê-lo como centro irradiador de poder, mas por considerá-lo uma das suas diferentes manifestações, que convive com múltiplas outras formas existentes em uma determinada sociedade. Isto porque o Estado, apesar do fascínio ou do horror que presentemente desperta, não foi sempre supervalorizado como hoje, nem sempre the foi atribuída a centralidade política que atualmente desfruta" (PEREIRA; RAMOS; SANTOS FILHO, 2011, p.22).

Portanto, a formulação de governamentalidade proposta por Foucault teve como objetivo específico analisar as mudanças no início do estado moderno como uma função das mudanças nas práticas do governo (GORDON, 1991). Ou seja, a governamentalidade referindo-se a uma filosofia de governo iniciada em um determinado período histórico (do século XVI ao XVIII), que culminou em uma reorientação radical na racionalidade e na prática da política ocidental. Em primeiro lugar, assumiu-se a população, e não o Estado, como objeto do governo e da economia política. Desse modo, a função do governo moderno passou a ser ordenar as relações econômicas e políticas do social para melhorar o bem-estar geral da população, ao invés de garantir a integridade de um território.

Aqui, o conceito de "racionalidade política" é fundamental. Ela é compreendida como um tipo particular de discurso. Ela representa um discurso que delimita em detalhes práticos um campo de governança - os assuntos, objetos e práticas a serem governados - e estabelece os meios apropriados pelos quais a governança deve ser realizada (MERLINGEN, 2010)2. Sendo assim, as racionalidades políticas produzem suas próprias problematizações ${ }^{3}$ definindo as

\footnotetext{
${ }^{2}$ Como aponta Merlingen (2010), diferente de outras análises de discurso em estudos políticos que se concentram em pronunciamentos públicos de atores governamentais, a teoria da governamentalidade se concentra nos discursos encontrados em documentos de políticas técnicas que tratam da governança de maneira programática.

3 Uma problematização não é um resumo neutro de uma situação atual, nem um resultado funcional necessário de um sistema social ou questão de política. Pelo contrário, é uma construção contingente moldada por suas condições ideacionais de emergência.
} 
ameaças e os desafios à boa governança e os efeitos adversos que podem ser esperados de quaisquer falhas ou deficiências.

Porém, de que modo essas racionalidades políticas são implementadas? Como elas penetram no tecido social? O conceito de "tecnologia política" refere-se às práticas e dispositivos através dos quais as racionalidades políticas são operacionalizadas e implementadas em programas e atividades de governança reais. Tecnologias políticas, nesse sentido, não se circunscrevem apenas a dispositivos físicos como relatórios, mas também, inclui tecnologias discursivas que visam (re) constituir identidades sociais, interesses e relações. Por meio de seu foco em tecnologias políticas, a teoria da governamentalidade destaca a dimensão material das práticas discursivas, incluindo operações técnicas através das quais a realidade é formada. Além disso, torna práticas e dispositivos aparentemente inócuos reconhecíveis como veículos de poder que moldam a governança e frequentemente atingem o tecido social (MERLINGEN, 2010).

Sendo assim, segundo a ótica da 'governamentalidade' existem diferentes e múltiplos processos que governam a conduta dos indivíduos, não sendo necessárias intervenções diretas por parte do governo. Tais processos são permeados e agrupados por uma 'mentalidade', uma racionalidade específica que se baseiam em teorias, filosofias, cálculos ou valores que são produtos sociais e culturais e são (re) produzidos nos processos de governar (DEAN, 2010). É nesse sentido que o famoso complexo "poder-saber" idealizado por Foucault aparece de modo latente. O saber (conhecimento) nesse sentido, faz parte do uso do poder, e este, por sua vez, produz conhecimento. Portanto, a governamentalidade aponta para o modo como os discursos estão entrelaçados com um campo de práticas que aparentemente diferentes e desconexas (METHMANN, 2011). Ou seja, ajuda a esclarecer as várias maneiras pelas quais o poder é exercido "à distância" além dos limites estreitos das políticas estatais (MILLER; ROSE, 2008).

Premissas reificadas como a de mercado, Estado e população são, de acordo com a interpretação da governamentalidade, são produtos de tecnologias de governo diferentes que vão do liberalismo clássico ao neoliberalismo (NADESAN, 2008). Não existe uma pressuposição de sua existência a priori. Sendo assim, autoridades diferentes, em períodos históricos diferentes, empregaram estratégias diversas delineando tais noções de mercado, Estado e população como esferas 
distintas. Logo, tais noções reificadas, e que amplamente fazem parte do vocabulário das RI são, para os teóricos da governamentalidade, instrumentos e efeitos de estratégias políticas, e que foram importantes para se definir dicotomias importantes como o externo/interno e o Estado/sociedade civil. Portanto, a governamentalidade lida com os aparatos estatais, mas sua análise política vai além deles, não terminando em uma determinada instituição (NADESAN, 2008). Sendo assim, uma análise pautada na ótica da governamentalidade precisa identificar alguns elementos básicos, entre eles: as diferenças formas de pensamento, suas condições de formação, os conhecimentos por eles gerados, assim como as práticas de governo a eles associadas (GORDON, 1991 apud PEREIRA; RAMOS; SANTOS FILHO, 2011).

\subsection{Governamentalidade $x$ Governança: um breve comparativo nas RI}

Apesar de apontar a governamentalidade como uma "alternativa" analítica, minha intenção não é a de promover qualquer tipo julgamento valorativo entre as duas abordagens. Por alternativa, compreendo uma forma diferente de examinar um fenômeno, podendo ela contribuir para a reflexão de outras formas de análise. Em grande parte, concordo com a afirmação de Höppner e Nagl (2007) de que governança e governamentalidade não devem permanecer independentes ou contraditórias, e sim, que elas podem ser combinadas de modo a se tornar mais produtivas. Segundo os autores, alguns pontos fortes característicos da abordagem da governamentalidade podem ser de grande valia para o entendimento da governança e do governar para além do Estado. Portanto, nesta seção tentarei sistematizar a contribuição da governamentalidade para as Relações Internacionais alguns dos possíveis pontos de diálogo, dissenso, e algumas aplicações dessa lente analítica na área.

Para Merlingen (2011), as teorias da governança e da governamentalidade se sobrepõem. Entre alguns pontos de consenso nestas abordagens estão: ambas se preocupam em analisar os problemas de governo da política global, ou seja, são uma certa forma de reação aos diferentes elementos dessa crise (AMOS, 2010; BEVIR, 2011). Com os desafios impostos pela globalização e pela desregulamentação neoliberal, que culminaram em mudança políticas, econômicas e sociais, novos desafios surgiram para os governos. Modelos clássicos de governo 
e governabilidade, principalmente nos países ocidentais, vem perdendo sua aplicabilidade prática e, consequentemente, vem sofrendo questionamentos teóricos (HÖPPNER; NAGL, 2007).

Portanto, ambas convergem em torno de uma questão central comum: as problemáticas de dirigir, regular, governar, conduzir etc. na sociedade moderna com relação a indivíduos, organizações, sistemas, estado e sociedade em geral. Utilizando-se dos dois conceitos, Amos (2010) analisou a relação entre o Estado e o sistema educacional. Seu intuito foi demonstrar que os ambos podem ser utilizados, e até combinados, como ferramentas analíticas para analisar as transformações atuais. Sendo assim, ele pontua que apesar de suas diferenças, ambas as perspectivas podem ser mescladas para discutir as implicações para a educação comparada.

Outro ponto que me parece comum é a intenção explícita de transcender os limites das teorias de governo centradas no Estado. Ambas abordagens se preocupam em abrir a caixa preta do Estado, dando maior atenção para a difusão do poder e da ação política. Para isso, exploram a porosidade que existe na fronteira entre Estado e sociedade civil. De outro modo, eles revelam os diversos atores, agências e discursos que constroem, mantêm e transformam a governança, e que vão além das funções estatais (BEVIR, 2011). Ambas enfatizam formas de regras caracterizadas como não hierárquicas, cooperação público-privada, papel das normas e formas de cooperação em rede de vários níveis. Além disso, a força das duas abordagens é fornecer um vocabulário descritivo para mapear novos atores, relações e práticas de segurança emergentes.

Entendendo que a teoria da governamentalidade seria uma ferramenta para estudar a governança em rede para além do estado, Merlingen (2011) à aplicou na governança interna e externa da Política Comum de Segurança e Defesa (PCSD) das sociedades pós-conflito. Tais casos demonstraram os tipos de perguntas de pesquisa, preocupações analíticas, argumentos, evidências empíricas e métodos que a pesquisa de governamentalidade exige, e os tipos de descobertas que ela pode gerar. Sendo assim, conclui identificando deficiências da teoria que seriam motivo de preocupação para alguns pesquisadores da PCSD. Ele se baseou na teoria da governamentalidade para elaborar uma agenda de pesquisa que se preocupasse principalmente com a dinâmica e o funcionamento da governança 
interna e externa da PCSD, e não com a PCSD como local e contribuinte para os processos de securitização.

Apesar de alguns pontos de sinergia, as duas chaves analíticas possuem focos e análises diferentes. Primeiramente, no que tange ao objeto de análise, a governança concentra-se na interação dinâmica entre estruturas e processos, instituições e atores, regras e sua aplicação. Sua intenção é capturar as complexidades dos arranjos institucionais e informais entre atores públicos e privados na tentativa de regular questões coletivas da política internacional (HÖPPNER; NAGL, 2007). Sendo assim, a análise da governança está mais preocupada com as questões técnicas, os instrumentos e modos, procedimentos e atores, com suas constelações e formas de cooperação. A partir disso, produz insights sobre a mudança de papéis e o significado dos estados soberanos no governo de assuntos globais ou transnacionais, além de teorizar sobre as formas de mudança e institucionalização da autoridade política (SENDING; NEUMANN, 2006). Esse movimento analítico possibilita analisar mudanças de modos de governar hierárquicos e baseados em soberania para modos de governar mais horizontais e baseados em rede. O uso do termo governança, em vez de governo, carrega conotações de descentralização, refletindo a incorporação de vários atores diferentes, afastando-se de uma compreensão hierárquica do governo e permitindo a identificação da governança como um processo multinível e multijurisdicional (INNES; STEELE, 2012). Ou seja, o governo deve ser estudado como um processo, não como uma instituição.

$\mathrm{Na}$ abordagem da governamentalidade, o Estado não é objeto do seu interesse, mas sim, a análise das técnicas de governança que o Estado é composto. Portanto, se propõe a identificar e descrever as conexões entre as tecnologias de governo, apontando diferentes técnicas que governam, mas não se baseia na soberania ou força, e sim, na intrincada rede de relações de poder presente (HÖPPNER; NAGL, 2007). Por outro lado, analisa historicamente como os problemas e tecnologias de governança são formulados e abordados. Apesar de também serem reduzidamente consideradas na literatura sobre governança, a governamentalidade fornece descrições extensas de técnicas discursivas que criam sujeitos, práticas de verdade e normalização, e processos de exclusão e inclusão discursiva (HÖPPNER; NAGL, 2007). Ou seja, oferece uma descrição muito mais 
detalhada das possibilidades de governar através do discurso. Portanto, ao invés de olhar para as instituições de governança, a governamentalidade se concentra nas táticas que os atores globais empregam para alcançar a auto governança no nível dos governados.

Baseando-se nessa perspectiva, Prakash se baseia tenta explicar o papel da ciência para a legitimidade e o exercício do poder colonial na Índia, enquanto mostra como as elites nacionalistas conseguiram sequestrar esses discursos científicos e usá-los para seus próprios fins (PRAKASH, 1999a). Já Scott interpreta o surgimento de novas estratégias governamentais na segunda metade do século XIX no sistema jurídico e escolar como uma tentativa de reestruturação consciente dos campos de ação sociais e individuais, com o objetivo de moldar a diligência, o comprometimento e a motivação dos assuntos coloniais (SCOTT, 1995). Ambas abordagens utilizam da governamentalidade para demonstrar como os sujeitos são criados e moldados pelas técnicas de governo.

Em segundo lugar, entre os pesquisadores que se utilizam da perspectiva foucaultiana, uma das principais críticas feitas às análises da governança (global) relaciona-se à necessidade de uma discussão mais substancial sobre à questão do poder, tema bastante caro às $\mathrm{RI}$, assim como ao arcabouço teórico foucaultiano (HÖPPNER; NAGL, 2007). Grande parte da solidez da ótica da governamentalidade está em se debruçar criticamente sobre as relações de poder. Diferente do debate normativamente carregado sobre governança, estudos pautados na governamentalidade levam em consideração o caráter horizontal, relacional e não hierárquico dessas relações.

Apesar de Czempiel (1992, p.50) ter afirmado que "os governos exercitam a regra, a governança usa o poder", o conceito de governança global ainda permaneceu alheio à questão do poder. Muito tempo depois da expansão dos estudos sobre governança, Adler; Bernstein (2005) e Barnett; Duvall (2005) ainda colocaram a relação "governança e poder" como um problema das análises de governança global. Trazendo a importância do que eles chamaram de "poder produtivo" ${ }^{4}$, ambos autores fizeram referência à contribuição de Foucault com o

\footnotetext{
${ }^{4}$ Poder produtivo "é a constituição de todos os sujeitos sociais com vários poderes sociais por meio de sistemas de conhecimento e práticas discursivas de amplo alcance geral e geral". "(...) O poder produtivo diz respeito ao discurso, aos processos sociais e aos sistemas de conhecimento através
} 
intuito de reformular o conceito de governança a partir da re-tematização de sua dimensão "política". Eles argumentam que o conceito de poder pode ser entendido em sentido disposicional, uma vez que "ordena" e "controla" sujeitos sociais, ou seja, em um sentido "produtivo", dado que define "a ordem das coisas" semanticamente, através do "discurso" (ADLER; BERNSTEIN, 2005, p. 294).

As análises da governança (global) não promovem uma discussão substancial sobre o poder, tema caro às RI como ao arcabouço teórico foucaultiano. Nesse ponto, as abordagens se divergem de modo evidente. Apesar de ambas evidenciarem a ascensão de diferentes atores não estatais, a abordagem da governança global, parte do pressuposto de que o poder emana do Estado. O que ocorre é uma transferência de poder do Estado para os atores não estatais, de modo que a política internacional, analisando a questão do poder, ainda seria pautada num jogo de soma zero. Divergente dessa interpretação, a governamentalidade repensa o entendimento convencional do poder nas RI. Aqui, o poder entendido como relacional. Ao invés de emanar verticalmente do Estado para os demais atores "abaixo" dele, o poder opera em um nível horizontal estabelecendo relações entre os indivíduos e os fins desejados. Ele cria, portanto, um ambiente de auto governança pelo qual aos indivíduos são dadas escolhas, e cabe a eles tomarem suas decisões. Desse modo, a governamentalidade gerencia a condutas dos indivíduos, sendo que, no nível global, os governados podem ser entendidos como indivíduos, estados, agências, organizações internacionais e transnacionais, autoridades privadas e assim por diante. O que diferencia essa conduta gerenciada e de um poder disciplinar (de imposição) é que a primeira está relacionada com o fornecimento de condições e oportunidades que dão liberdade à decisão do comportamento político. Nesse caso, o que o "disciplina" não é a ameaça de uma punição, e sim, o risco potencial de fazer uma escolha equivocada.

Estudos de governança global focam na diferença do poder relativo entre os Estados e os atores não estatais, e apontam para uma autoridade política cada vez mais institucionalizada em esferas não controladas pelos estados (SENDING; NEUMANN, 2006). Os autores questionam tais pressupostos concentrando-se nos processos sociopolíticos da governança e buscando identificar sua racionalidade como práticas de governo. Através da ótica da governamentalidade, eles tratam o

dos quais o significado é produzido, fixo, vivido, experimentado e transformado" (BARNETT; DUVALL, 2005, p.20, trad. nossa). 
papel dos atores não estatais na governança global como expressão de uma lógica de governo pelo qual a sociedade civil é redefinida a partir de um objeto passivo de governo para ser atuada em uma entidade que é ao mesmo tempo um objeto e um sujeito do governo (SENDING; NEUMANN, 2006).

Desafiando um dos principais pressupostos dos estudos de governança global, de que o Estado perdeu poder para atores não estatais e a autoridade política é cada vez mais institucionalizada em esferas não controladas pelos Estados, Sending e Neumann (2006) utilizam da noção de governamentalidade procurando identificar a racionalidade como práticas de governo político. Sendo assim, o papel de atores não estatais na formação e execução de funções de governança global não é um exemplo de transferência de poder do estado para atores não estatais, mas antes uma expressão de uma lógica ou racionalidade de governo em mudança pela qual a sociedade civil é redefinida a partir de um objeto passivo de governo para ser atuada em uma entidade que é ao mesmo tempo um objeto e um sujeito do governo. Para tanto, eles abordam dois estudos de caso: a campanha internacional para proibir minas terrestres e a política populacional internacional. Os casos mostram que a sociedade civil é cada vez mais definida como um campo povoado por sujeitos políticos cuja autonomia, experiência e capacidade de canalizar responsavelmente a formação da vontade política se tornaram cruciais para as tarefas de governo. Identificamos uma racionalidade governamental em que o poder político opera através da sociedade civil e não na sociedade. O governo é realizado através de assuntos autônomos, não em objetos passivos.

Em outro texto, Sending e Neumann (2010) apontam que papel das Organizações Internacionais (Ol's) ou das Organizações não governamentais na configuração e execução das funções de governança global não é um exemplo de transferência de poder do Estado para atores não estatais. Por outro lado, seria a expressão de uma lógica ou racionalidade de mudança do governo (definida como um tipo de poder) pela qual a sociedade civil é redefinida a partir de um objeto passivo de governo a ser atuado e em uma entidade que é ao mesmo tempo um objeto e um assunto de governo. Da mesma forma, essa racionalidade de governo atribui às Ol's uma posição central, não apenas devido aos objetivos liberais que 
costumam adiantar, mas também, por causa da escala global de seu modo de governar (SENDING; NEUMANN, 2010).

Por último, juntamente com a questão do poder, está atrelada a noção de autoridade política e a ascensão de novos atores não estatais na esfera internacional. Dentro da abordagem da governança, alguns autores veem a importância e autoridade do Estado em governar diminuindo, outros preferem falar de uma alteração em seu papel. O objetivo desse debate era permitir uma melhor compreensão de governar onde o Estado não é o único ator relevante. Ele permaneceu, no entanto, um dos atores importantes e presença em todas as principais discussões. Para os casos empíricos em questão, isso foi amplamente problemático, porque o estado se mostrou um fenômeno empírico persistente. No entanto, existem limites para a aplicabilidade dessa suposição. Enquanto o Estado, teoricamente, está presente em quase todos os lugares, sua presença empírica em grandes partes do mundo é fragmentária, na melhor das hipóteses. A autoridade política é cada vez mais desalojada do estado soberano e na direção das redes de políticas transnacionais e das "esferas de autoridade" funcionalmente específicas, onde o Estado desempenha um papel estratégico, mas não necessariamente dominante. Portanto, os estudos de governança global perpetuam a mesma estrutura analítica que pretendem transcender como suas principais descobertas. $O$ poder dos atores não estatais e a difusão da autoridade política do Estado para outros atores são parasitas de uma estrutura analítica ligada à tríade entre soberania, autoridade e legitimidade.

Nas análises da governamentalidade, a ascensão da sociedade civil e a crescente importância dos atores não-governamentais, em vez de sinalizar o fim do governo pelo Estado ou uma redução na sua autoridade, representam uma nova racionalidade do governo, oferecendo maneiras mais sofisticadas de incorporar resistência e legitimar o governo. A Sociedade Civil Global, por exemplo, canaliza muitos dos desafios da política global e permite regras relativamente ordenadas em muitas áreas. No entanto, essas funções não estão apenas ou principalmente atuando como restrições do poder, mas são amplamente produtivas no sentido de que produzem novas formas de ação, política e novos espaços de luta política (LIPSCHUTZ, 2005), dando um caráter produtivo à governamentalidade. 
Methmann (2011) argumenta que as tentativas de tornar a mudança climática algo governável é um exemplo perfeito de uma governamentalidade genuinamente global, pois é construída em um espaço de problemas globais. Trabalhando com a "governamentalidade do carbono", ele aponta que ela não afeta apenas a política internacional, mas também pode gerir a conduta dos sujeitos em vários níveis espaciais e políticos através desde o "orçamento de carbono" pessoais e o "coletor nacional" até os mercados transnacionais de carbono.

Outra força da perspectiva da governamentalidade sobre as técnicas de governo reside no tratamento da resistência. Como O'Malley salienta, a resistência a programas governamentais não pode ser reduzida a um mero obstáculo à sua implementação bem-sucedida que força a reformulação desses programas. A concepção produtiva de poder desenvolvida por Foucault nos permite entender as lutas sociais como parte integrante e constitutiva do próprio processo de governança. Ele descreve isso com relação à incorporação de estruturas de auto governança indígena em programas governamentais australianos que levam a uma forma sutil, aparentemente voluntária e descentralizada de 'governança à distância' dessas comunidades aborígines (O'MALLEY, 1996). Essa perspectiva também nos impede de desenvolver uma interpretação aparentemente racional e coerente dos programas governamentais, porque inclui as contradições e ambivalências enquanto aponta para possíveis pontos de partida para intervenções políticas críticas.

\section{Considerações Finais}

Como apontei durante a exposição, tanto o conceito de governança global, quanto o de governamentalidade, são úteis para analisar e compreender as mudanças que ocorreram no cenário internacional com o processo de globalização. Alguns autores apontam que ambas abordagens têm como intuito fazer frente às crises de governo e a incapacidade do Estado em gerir todos os problemas derivados das mudanças econômicas, políticas e sociais que ocorreram nas últimas décadas. Portanto, trazer à tona a ascensão dos atores não estatais, assim como, entender como eles ganharam novos papeis e funções, é uma característica fundamental das teorias apresentadas no campo das Relações Internacionais. 
A pretensão em dar mais atenção aos atores não estatais, representa uma tentativa de descentralizar as análises no Estado como o único, ou o principal, ator relevante. No entanto, os estudos da governança global não conseguiram, de fato, quebrar esse vínculo com as abordagens tradicionais. Apesar de demonstrarem a importância dos atores não estatais, e principalmente, da sociedade civil, os teóricos da governança ainda continuaram fortemente arraigados à tríade "soberania, autoridade e legitimidade". Portanto suas concepções de poder e autoridade ainda respondem aos pressupostos positivistas e tradicionais da disciplina.

Meu argumento é que, o conceito de governamentalidade, tem valor e potencial para contribuir com o campo das Relações Internacionais de algumas maneiras. O valor acrescentado da teoria da governamentalidade nos estudos internacionalistas é expresso na sua capacidade de desconstruir e questionar aquilo que é "tomado como garantido". O "discurso" sobre governança é parte integrante de seu próprio "funcionamento", e não um meio de legitimação "externa" à racionalidade do governo, operando em uma determinada configuração de poder (DEAN, 2010). Tal análise desvela o domínio político de seu caráter evidente, normal ou natural, que é essencial para o seu funcionamento" (MERLINGEN, 2006, p.188, trad. Nossa). Neste contexto, há uma outra oportunidade para aplicar a abordagem de governamentalidade à governança global, realizando uma análise crítica que aborda a despolitização da política global de acordo com o paradigma de "governança sem governo", revelando seu caráter "político" (PROZOROV, 2004).

Outra contribuição importante é que os estudos sobre governamentalidade partem de uma noção de poder que se diferencia, e muito, da acepção utilizada nas teorias tradicionais de Relações Internacionais. A "mecânica do poder", utilizando a expressão de Foucault, trata do poder como posse de recursos e/ou capacidades. De outro modo, é um poder negativo, que remete ao controle, sujeição. Ou seja, um poder verticalizado, que se exerce de cima para baixo. De modo distinto, a governamentalidade tem suas raízes em uma noção de poder diferente. A "analítica do poder" trata do poder como uma rede produtiva que permeia a sociedade produzindo discursos e conhecimento, é um poder positivo. Ele não se irradia de um centro até os níveis inferiores como em uma hierarquia. Ao contrário, ele é abstraído das capilaridades, das formas terminais, deslocando-se por toda sociedade de maneira plural, heterogenia e não hierárquica. Ou seja, o poder é fluido, relacional, 
produtivo, construindo e controlando os sujeitos, mas sem se concentrar nem emanar de um centro. É distinto da ideia de dominação/sujeição, pressuposta na ideia de poder como algo que se detém.

Interpretando o poder de tal modo, a abordagem da governamentalidade permite que se possa quebrar a tríade mencionada anteriormente. O Estado deixa de ser o detentor, o centro que emana e que controla o poder. O que os teóricos da governança global chamam de "transferência de poder do Estado para atores não estatais", ou o "fim do governo pelo Estado" é, na verdade, a expressão de uma lógica ou racionalidade variável do governo (um tipo de poder) pela qual a sociedade civil é redefinida a partir de um objeto passivo do governo para ser atuada sobre uma entidade que é um objeto e um sujeito do governo. Sendo assim, oferece maneiras mais sofisticadas de incorporar resistência e legitimar o governo.

Ao entender que o poder não é exercido por uma instituição ou Estado, e sim, algo que flui pela sociedade, que ao mesmo tempo que controla também produz novas práticas e interações, a análise da governamentalidade quebra com a imagem do Estado monolítico, uma "caixa preta". Portanto, traz outra visão sobre questão da soberania e do poder, pilares da disciplina de Relações Internacionais.

Em relação à questão do poder e autoridade nas Relações Internacionais, temos duas contribuições importantes por parte da ótica da governamentalidade. Uma primeira diz respeito ao deslocamento do Estado como um centro de onde emana-se o poder. Ao entender que o poder não é exercido por uma instituição ou Estado, e sim, algo que flui pela sociedade, que ao mesmo tempo que controla também produz novas práticas e interações, a análise da governamentalidade quebra com a imagem do Estado monolítico, uma "caixa preta". Consequentemente, e essa é uma segunda contribuição, desconstrói-se o poder como algo que se detém, seja capacidades e/ou recursos, algo caríssimo às abordagens mais tradicionais das $\mathrm{RI}$.

Obviamente, e me parece importante ressaltar, a aplicação do conceito de governança suscitou diversas críticas. Alguns autores apontaram preocupações relativas à aplicabilidade do conceito de governamentalidade ao âmbito internacional (CHANDLER, 2009; JOSEPH, 2009, 2010; SELBY, 2007). Apesar de já haver uma literatura que se propõe a responder a tais questionamentos (NEWMANN; SENDING, 2007; VRASTI, 2013), chamo atenção e concordo com o argumento de 
Pereira; Ramos; Santos Filho (2011). Segundo os autores, para que se possa utilizar o conceito de governamentalidade nas RI, é necessário que se defina claramente conceito, o objeto e os modos de utilizá-lo, para que não se incorra no que ele colocou como "consenso ortodoxo", que pauta as teorias mais tradicionais de Relações Internacionais.

Por fim, não foi meu intuito aqui tentar fazer do conceito de "governamentalidade" a solução para as limitações do conceito de governança global, e até mesmo, das análises de Relações Internacionais. O que tentei demonstrar é que os estudos da governamentalidade, apesar de recentes na disciplina, estão sendo férteis na área. Além de estabelecer uma crítica a postulados e conceitos reificados das $\mathrm{RI}$, tais estudos também nos impulsionam a tentar compreender um pouco melhor os discursos subjacentes em diversos temas que consideramos como dados. Além de abrir novas agendas de pesquisa, estudos da governamentalidade podem servir como interlocutores, críticos, importantes para o crescimento da pesquisa em torno da política internacional. Mais importante ainda, tal discussão já tomou corpo em diversos lugares e instituições. Porém, no Brasil, ainda existe uma certa resistência em relação à utilização do conceito e de um debate sobre as perspectivas e ganhos analíticos que podemos ter. Portanto, o artigo teve como objetivo central tentar trazer um pouco dessa "nova perspectiva" para o debate brasileiro e incentivar as pesquisas e o debate acerca de diferentes formas de se interpretar as mudanças ocorridas na política internacional atualmente.

\section{Referências}

ABBOTT, Kenneth. W.; SNIDAL, Duncan. Hard and soft law in international governance. International organization, v. 54, n. 3, p. 421-456, 2000.

ADLER, Emanuel; BERNSTEIN, Steven. Knowledge in power: the epistemic construction of global governance. In: BARNETT, Michael. N.; DUVALL, Raymond. Power in global governance, Cambridge: Cambridge University Press, p. 294, 2005.

BARNETT, Michael. N.; DUVALL, Raymond. Power in global governance. Cambridge: Cambridge University Press, 2005. 
BENEDETTI, Fanny; WASHBURN, John L. Drafting the International Criminal Court treaty: Two years to Rome and an afterword on the Rome diplomatic conference. Global Governance, v. 5, p. 1, 1999.

BETTS, Alexander (Ed.). Global migration governance. Oxford University Press, 2011.

BEVIR, Mark. Governance and governmentality after neoliberalism. Policy \& Politics, v. 39, n. 4, p. 457-471, 2011.

BIERMANN, Frank; SIEBENHÜNER, Bernd; SCHREYÖGG, Anna. Global environmental governance and international organizations: Setting the stage. In: BIERMANN, Frank; SIEBENHÜNER, Bernd; SCHREYÖGG, Anna. International Organizations in Global Environmental Governance. Routledge, p. 15-30, 2009.

BIERMANN, Frank; PATTBERG, Phillip H. (Ed.). Global environmental governance reconsidered. MIT Press, 2012.

BIERSTEKER, Thomas. J. Global governance. In CAVELTY, Myriam. D; MAUER, Victor. The Routledge handbook of security studies. London: Routledge, p. 439-452, 2010.

BÖRZEL, Tanja A.; RISSE, Thomas. Public-private partnerships: Effective and legitimate tools of international governance. In GRANDE, Edgar; PAULY, Louis W. (Ed.). Complex sovereignty: Reconstructing political authority in the twenty first century. Toronto: University of Toronto Press, p. 195-216, 2005.

BUCHANAN, Allen; KEOHANE, Robert $O$. The legitimacy of global governance institutions. Ethics \& international affairs, v. 20, n. 4, p. 405-437, 2006.

CHANDLER, David. Critiquing liberal cosmopolitanism? The limits of the biopolitical approach. International Political Sociology, v. 3, n. 1, p. 53-70, 2009.

CLAPP, Jennifer; FUCHS, Doris. Agrifood corporations, global governance, and sustainability: a framework for analysis. Corporate power in global agrifood governance, p. 1-26, 2009.

COMMISSION ON GLOBAL GOVERNANCE. Our Global Neighbourhood, New York: Oxford University Press, 1995.

COX, Robert. W. Production, power, and world order: Social forces in the making of history. Columbia University Press, 1987.

CUTLER, A. Claire.; HAUFLER, Virginia; PORTER, Tony. (Ed.). Private authority and international affairs. Suny Press, 1999.

CZEMPIEL, Ernst. Governance and democratization. In: ROSENAU, James N.; CZEMPIEL, Ernst. (Ed.) Governance without government: Order and change in world politics, p. 250-71, 1992.

DEAN, Mitchell. Governmentality: Power and rule in modern society. London: Sage Publications, 1999. 
DEAN, Mitchell; HINDESS, Barry. (Ed.). Governing Australia: Studies in contemporary rationalities of government. Cambridge University Press, 1998.

DEATH, Carl. Governmentality at the limits of the international: African politics and Foucauldian theory. Review of International Studies, v. 39, n. 3, p. 763-787, 2013.

DE LARRINAGA, Miguel; DOUCET, Marc G. (Ed.). Security and global governmentality: Political Science Quarterly globalization, governance and the state. Routledge, 2010.

DILLON, Michael; REID, Julian. Global liberal governance: Biopolitics, security and war. Millennium, v. 30, n. 1, p. 41-66, 2001.

DINGWERTH, Klaus; PATTBERG, Phillip. Global governance as a perspective on world politics. Global Governance, v. 12, p. 185, 2006.

DREZNER, Daniel W. The global governance of the Internet: Bringing the state back in. Political Science Quarterly, v. 119, n. 3, p. 477-498, 2004.

DUFFIELD, Mark. Global governance and the new wars: The merging of development and security. Zed Books Ltd., 2014.

EAGLETON-PIERCE, Matthew. The concept of governance in the spirit of capitalism. Critical Policy Studies, v. 8, n. 1, p. 5-21, 2014.

FALKNER, Robert. Private environmental governance and international relations: exploring the links. Global environmental politics, v. 3, n. 2, p. 72-87, 2003.

FINNEMORE, Martha; SIKKINK, Kathryn. International norm dynamics and political change. International Organization, v. 52, n. 4, p. 887-917, 1998.

FINKELSTEIN, Larry S. What is global governance. Global governance, v. 1, p. 367 , 1995.

FOUCAULT, Michel. Genealogia e Poder. In: MACHADO, Roberto. (org.) Microfísica do Poder. $6^{\mathrm{a}}$ edição. Rio de Janeiro: Edições Graal, 1986.

FOUGNER, Tore. Corporate power in world politics: the case of the world economic forum. The Journal of International Trade and Diplomacy, v. 2, n. 2, p. 97-134, 2008.

FRASER, Nancy. From discipline to flexibilization? Rereading Foucault in the shadow of globalization. Constellations, v. 10, n. 2, p. 160-171, 2003.

GILL, Stephen. Structural Change and Global Political Economy: Globalizing Elites and the Emerging World Order. SAKAMOTO, Y (Ed.). In Global Transformation: Challenges to the State System. Tokyo: United Nations University Press, 1994.

GOLDMAN, Michael. Imperial Nature: The World Bank and Struggles for Social Justice

in the Age of Globalization, New Haven, CT and London: Yale University Press, 2005. 
GORDENKER, Leon. Pluralising global governance: analytical approaches and dimensions. Third world quarterly, v. 16, n. 3, p. 357-388, 1995.

GORDON, Collin. Governmental rationality: An introduction. In Burchell, G.; Gordon, C.; Miller, P. The Foucault effect: Studies in governmentality, p. 1-51, 1991.

GRAZ, Jean. C. How powerful are transnational elite clubs? The social myth of the World Economic Forum. New Political Economy, v. 8, n. 3, p. 321-340, 2003.

HAAS, Peter. M. Introduction: epistemic communities and international policy coordination. International organization, v. 46, n. 1, p. 1-35, 1992.

HAAS, Peter. M. Social constructivism and the evolution of multilateral environmental governance. In: PRAKASH, A.; HART, J. A. Globalization and governance. London: Routledge, p. 103-134, 1999.

HAFNER-BURTON, Emilie; POLLACK, Mark A. Mainstreaming gender in global governance. European Journal of International Relations, v. 8, n. 3, p. 339-373, 2002.

HALL, Robert. B.; BIERSTEKER, Thomas. J. (Ed.). The emergence of private authority in global governance. Cambridge University Press, 2002.

HELD, David; MCGREW, Anthony. Introduction. In HELD, David; MCGREW, Anthony. (Ed), Governing Globalisation, Cambridge, Polity Press, p. 1-21, 2002.

HEWSON, Martin; SINCLAIR, Timothy. J. (Ed.). Approaches to global governance theory. Suny Press, 1999.

JESSOP, Bob. The regulation approach, governance and post-Fordism: alternative perspectives on economic and political change?. Economy and society, v. 24, n. 3, p. 307-333, 1995.

JOSEPH, Jonathan. Governmentality of what? Populations, states and international organisations. Global Society, v. 23, n. 4, p. 413-427, 2009.

JOSEPH, Jonathan. What can governmentality do for IR?. International Political Sociology, v. 4, n. 2, p. 202-205, 2010.

KAHLER, M. Rising powers and global governance: negotiating change in a resilient status quo. International Affairs, v. 89, n. 3, p. 711-729, 2013.

KECK, Margaret. E.; SIKKINK, Kathryn. Transnational advocacy networks in international politics: Introduction. In KECK, Margaret E.; SIKKINK, Kathryn. Activists Beyond Borders: Advocacy networks in international politics. p. 1-38, 1998.

KEOHANE, Robert. O.; NYE, Joseph. S. Transnational relations and world politics. Harvard University Press, 1972.

KEOHANE, Robert. O.; NYE, Joseph. S. Power and interdependence. Boston: Little, Brown ,1977. 
KEOHANE, Robert. O. After hegemony. Princeton: Princeton University Press, 1984.

KEOHANE, Robert. O. International institutions: Two approaches. International studies quarterly, v. 32, n. 4, p. 379-396, 1988.

KOENIG-ARCHIBUGI, Mathias. Mapping global governance. HELD, David; MCGREW, Anthony. Governing globalization: power, authority and global governance, p. 46-69, 2002.

KRASNER, Stephen. D. (Ed.). International regimes. Cornell University Press, 1983.

LAKE, David. A. Global Governance: a relational contracting approach. Globalization and governance. In: PRAKASH, Aseem; HART, Jeffrey. A. Globalization and governance. London: Routledge, p. 31-54, 1999.

LARNER, Wendy; WALTERS, Willian. Introduction: Global governmentality: governing international spaces. In LARNER, Wendy; WALTERS, Willian. (Ed). Global governmentality: Governing international spaces. Routledge, p. 1-21, 2004.

LATHAM, Robert. Politics in a floating world: toward a critique of global governance. In HEWSON, Martin; SINCLAIR, Timothy. J. (Ed.). Approaches to global governance theory. Suny Press, p. 23-53, 1999.

LEMKE, Thomas. Foucault, governmentality, and critique. London: Routledge, 2015.

LEVY, David. L.; PRAKASH, Aseem. Bargains old and new: Multinational corporations in global governance. Business and Politics, v. 5, n. 2, p. 131-150, 2003.

LIPSCHUTZ, Ronnie D. Reconstructing world politics: the emergence of global civil society. Millennium, v. 21, n. 3, p. 389-420, 1992.

LIPSCHUTZ, Ronnie D; MAYER, Judith. Global civil society and global environmental governance: The politics of nature from place to planet. Suny Press, 1996.

LIPSCHUTZ, Ronnie D. Global civil society and global governmentality: or, the search for politics and the state amidst the capillaries of social power. In: BARNETT, Michael N.; DUVALL, Raymond. Power in global governance, Cambridge: Cambridge University Press, p. 229-248, 2005.

LIPSCHUTZ, Ronnie D.; ROWE, James K. Globalization, governmentality and global politics: regulation for the rest of us?. Psychology Press, 2005.

MERLINGEN, Michel. Governmentality: Towards a Foucauldian framework for the study of IGOs. Cooperation and Conflict, v. 38, n. 4, p. 361-384, 2003.

MERLINGEN Michel. Foucault and world Politics: promises and challenges of extending governmentality theory to the European and beyond. Millennium, v. 35, n. 1, p. 181-196, 2006. 
MERRY, Sally E.; CONLEY, John M. Measuring the world: Indicators, human rights, and global governance. Current Anthropology, v. 52, n. S3, p. 83-95, 2011.

METHMANN, Chris. The sky is the limit: Global warming as global governmentality. European Journal of International Relations, v. 19, n. 1, p. 69-91, 2011.

MILLER, Peter; ROSE, Nikolas. Governing the present: Administering economic, social and personal life. Polity, 2008.

MURPHY, Craig. N.; YATES, Joanne. The International Organization for Standardization (ISO): global governance through voluntary consensus. Routledge, 2009.

NEUMANN, Iver B.; SENDING, Ole J. Governing the global polity: Practice, mentality, rationality. University of Michigan Press, 2010.

OHMAE, Kenichi. The borderless world: Power and strategy in the interlinked economy. London: Harper Collins, 1990.

O'MALLEY, Pat. Indigenous governance. International Journal of Human Resource Management, v. 25, n. 3, p. 310-326, 1996.

OVERBEEK, Henk. Global governance, class, hegemony. Contending Perspectives on Global Governance. Coherence and Contestation, v. 39, 2005.

PARK, Susan. Socialization, the World Bank group and global environmental governance. In: BIERMANN, Frank; SIEBENHÜNER, Bernd; SCHREYÖGG, Anna (Ed.). International Organizations in Global Environmental Governance. Routledge, p. 91-110, 2009.

PEREIRA, Chyara Sales; RAMOS, Leonardo César Souza; SANTOS FILHO, Onofre dos. Governança global, governamentalidade e uma nova visão acerca da relação entre explicação e compreensão nas Relações Internacionais. In: $3^{\circ}$ ENCONTRO NACIONAL ABRI 2011, 3, 2011, São Paulo.

PRAKASH, Gyan. Another Reason. Science and the Imagination of Modern India. Princeton, NJ: Princeton University Press, 1999.

PROZOROV, Sergei. Three theses on 'governance' and the political. Journal of International Relations and Development, v. 7, n. 3, p. 267-293, 2004.

REINICKE, Wolfgang H.; DENG, Francis. Critical choices: The United Nations, networks, and the future of global governance. IDRC, Ottawa, 2000.

RHODES, Roderick A. W. The new governance: governing without government. Political studies, v. 44, n. 4, p. 652-667, 1996.

ROSENAU, James. N.; CZEMPIEL, Ernst. (Ed.). Governance without government: order and change in world politics. Cambridge: Cambridge University Press, 1992. 
ROSENAU, James. N. "Governance in the Twenty-First Century". In WEISS, Thomas. G. Global Governance: A Review of Multilateralism and International Organizations, 1995.

ROSENOW, Doerthe. Decentring global power: The merits of a Foucauldian approach to international relations. Global Society, v. 23, n. 4, p. 497-517, 2009.

RUGGIE, John. G. International regimes, transactions, and change: embedded liberalism in the postwar economic order. International organization, v. 36, n. 2, p. 379-415, 1982.

SANDHOLTZ, Wayne. Globalization and the Evolution of Rules. In: PRAKASH, Aseem; HART, Jeffrey A. Globalization and governance. London: Routledge, p. 77$102,1999$.

SCHIAVO, Lidia L. Governance, Civil Society, Governmentality. The 'Foucauldian Moment' in the Globalization Debate: Theoretical Perspectives. International Journal of Humanities and Social Science, v. 4, n. 13, p. 1-17, 2014.

SCHOLTE, Jan. A. Civil society and democracy in global governance. Global Governance, v. 8, n. 3, p. 281-304, 2002.

SCOTT, David. Colonial governmentality. Anthropologies of modernity: Foucault, governmentality, and life politics, p. 23-49, 2005.

SELBY, Jan. Engaging Foucault: Discourse, liberal governance and the limits of Foucauldian IR. International Relations, v. 21, n. 3, p. 324-345, 2007.

SENDING, Ole J.; NEUMANN, Iver. B. Governance to governmentality: Analyzing NGOs, states, and power. International studies quarterly, v. 50, n. 3, p. 651-672, 2006 .

TELÒ, Mario (Ed.). European Union and new regionalism: regional actors and global governance in a post-hegemonic era. Ashgate Publishing, Ltd., 2013.

THOMPSON, Grahame; HIRST, Paul. Globalization in question: the international economy and the possibilities of governance. Polity Press, 1999.

VAN DER PIJL, Kees. Transnational classes and international relations. London: Routledge, 1998.

VRASTI, Wanda. Universal but not truly 'global': governmentality, economic liberalism, and the international. Review of International Studies, v. 39, n. 1, p. 49-69, 2013.

WALTERS, Willian; HAAHR, Jens. H. Governmentality and political studies. European Political Science, v. 4, n. 3, p. 288-300, 2005.

WEISS, Thomas. G. Governance, good governance and global governance: conceptual and actual challenges. Third world quarterly, v. 21, n. 5, p. 795-814, 2000. 
WEISS, Thomas. G.; GORDENKER, Leon. (Ed). NGOs, the UN, and global governance. Lynne Rienner, 1996.

WEISS, Thomas. G.; WILKINSON, Rorden. Global governance to the rescue: Saving international relations?. Global Governance, p. 19-36, 2014.

YOUNG, Oran R. International governance: protecting the environment in a stateless society. Cornell University Press, 1994.

ZANOTTI, Laura. Governmentalizing the post-Cold War international regime: The UN debate on democratization and good governance. Alternatives, v. 30, n. 4, p. 461-487, 2005. 